\title{
TREATMENTS FOR PARTIAL DEAFNESS USING COMBINED ELECTRIC AND ACOUSTIC STIMULATION OF THE AUDITORY SYSTEM
}

\section{Blake S. Wilson}

Co-Director, Duke Hearing Center, Duke University Medical Center, Durham, NC, USA; Adjunct Professor, Department of Surgery, DUMC; Adjunct Professor, Department of Electrical \& Computer Engineering, Duke University; Chief Strategy Advisor, Med-El Medical Electronics GmbH, Innsbruck, Austria; The Overseas Expert, Marie Curie Project for the Remediation of Hearing Loss, five centers in Europe including the primary site at the International Center of Hearing and Speech in Kajetany, Poland; Senior Fellow Emeritus, RTI International (previously known as the Research Triangle Institute), Research Triangle Park, NC, USA

Corresponding author: Prof. Blake S. Wilson, e-mail: blake.wilson@duke.edu

\begin{abstract}
This paper provides a summary of the experience to date with (1) combined electric and acoustic stimulation of the auditory system (combined EAS) for persons with some residual hearing at low frequencies, and (2) a procedure called "partial deafness cochlear implantation" (PDCI) for persons with higher levels of residual hearing at low frequencies, including persons with normal or nearly normal hearing at $500 \mathrm{~Hz}$ and lower frequencies. The paper also presents new results on the dependence of outcomes according to the levels of the residual hearing. In broad terms, both combined EAS and PDCI are highly beneficial treatments, especially for speech reception in noise. In some cases synergistic effects are found, in which the speech reception score for combined EAS or PDCI is greater than the sum of the scores for electric or acoustic stimulation only. In addition, the new results demonstrate that patients with high levels of residual hearing (PDCI levels) receive benefits from cochlear implantation that are at least as great as the benefits received by patients with lower levels of residual hearing. This finding strongly supports the concept of providing cochlear implants for persons with substantial residual hearing at low frequencies; indeed, a "point of diminishing returns" has yet to be identified.
\end{abstract}

key words: electric-acoustic stimulation $\bullet$ cochlear implant $\bullet$ partial deafness $\bullet$ partial deafness cochlear implantation $\bullet$ hearing preservation $\bullet$ auditory prostheses

\section{EL TRATAMIENTO DE SORDERA PARCIAL POR UTILIZACIÓN DE COMBINACIÓN DE ESTÍMULOS ELÉCTRICO Y ACÚSTICO DEL SISTEMA AUDITIVO}

\section{Resumen}

Este documento ofrece un resumen de la experiencia hasta la fecha con (1) la estimulación combinada eléctrica y acústica del sistema auditivo (estimulación combinada EAS) para las personas con audición residual en las frecuencias bajas, y (2) el procedimiento llamado „implantación coclear en hipoacusia” (PDCI) para las personas con niveles más altos de la audición residual en las frecuencias bajas, incluidas las personas con audición normal o casi normal a $500 \mathrm{~Hz}$ y a frecuencias más bajas. El documento también presenta nuevos resultados en la dependencia de los resultados de acuerdo a los niveles de la audición residual. En términos generales, tanto la estimulación combinada EAS, como la implantación PDCI son tratamientos muy beneficiosos, especialmente para la recepción del habla en ambientes de ruido. En algunos casos se observan efectos sinérgicos, en los que la puntuación de recepción de habla para la estimulación combinada EAS o la implantación PDCI es mayor que la suma de las puntuaciones resultantes únicamente de la estimulación eléctrica o acústica. Además, los nuevos resultados demuestran que los pacientes con altos niveles de audición residual (niveles PDCI) reciben beneficios de los implantes cocleares al menos tan grandes como los beneficios recibidos por los pacientes con niveles más bajos de la audición residual. Este hallazgo apoya el concepto de proporcionar implantes cocleares a personas con audición residual sustancial a bajas frecuencias, de hecho, el „punto de rendimientos decrecientes” aún no se ha identificado.

Palabras clave: estimulación electro-acústica • implante coclear • sordera parcial • implantación coclear en hipoacusia • preservación de la audición $\bullet$ prótesis auditivas 


\title{
TRAITEMENT DE LA SURDITÉ PARTIELLE À L'AIDE DE LA STIMULATION HYBRIDE ÉLECTRIQUE ET ACOUSTIQUE DU SYSTĖME AUDITIF
}

\begin{abstract}
Résumé
Ce document fournit un résumé de l'expérience à ce jour avec (1) la stimulation combinée électrique et acoustique du système auditif (EAS combinée) pour les personnes qui ont une certaine audition résiduelle en basses fréquences, et (2) une procédure appelée «implantation cochléaire dans le traitement de la surdité partielle» (PDCI) pour les personnes ayant des niveaux plus élevés d’audition résiduelle en basses fréquences, y compris les personnes ayant une audition normale ou presque normale à $500 \mathrm{~Hz}$ et aux fréquences plus basses. Ce document présente également les nouveaux résultats sur la dépendance des effetsen fonction des niveaux de l'audition résiduelle. En termes généraux, les deux traitements (EAS combinée et PDCI) sont très bénéfiques, en particulier pour la perception de la parole dans le bruit. Dans certains cas, les effets synergiques ont été constatés, car le résultat obtenu par la perception de la parole pour l'EAS combinée ou pour la PDCI est supérieur à la somme des résultats pour la stimulation seule électrique ou acoustique. En outre, les nouveaux résultats indiquent que les patients avec des niveaux élevés d’audition résiduelle (niveaux PDCI) bénéficient des effets de l'implantation cochléaire au moins autant que les patients ayant un niveau plus faible d'audition résiduelle. Cette constatation confirme l'idée d’offrir des implants cochléaires aux personnes ayant une audition substantielle en basses fréquences; cependant, les critères limites n’ont pas encore été identifiés.
\end{abstract}

Mots clés: stimulation électro-acoustique • implant cochléaire • surdité partielle • implantation cochléaire en surdité partielle - préservation de l'audition • prothèses auditives

\section{ЛЕЧЕНИЕ ЧАСТИЧНОЙ ГЛУХОТЫ, ИСПОЛЬЗУЯ КОМБИНАЦИЮ ЭЛЕКТРИЧЕСКОЙ И АКУСТИЧЕСКОЙ СТИМУЛЯЦИИ СЛУХОВОЙ СЕНСОРНОЙ СИСТЕМЫ}

\begin{abstract}
Краткий обзор
В данной статье приводятся доступные на сегодняшний день данные, посвященные (1) комбинированной электрической и акустической стимуляции слухового анализатора (комбинированная EAS) пациентов с остаточной слышимостью в диапазоне низких частот, и (2) методике, называемой «кохлеарная имплантация при частичной глухоте» (PDCI) у пациентов с повышенными уровнями остаточной слышимости при низких частотах, в том числе у пациентов с нормальной или близкой к норме остротой слуха при частоте 500 Гц и выше. В работе также представлены новые результаты относительно зависимости результата от уровня остаточной слышимости. В общих чертах, комбинированной EAS и PDCI свойственна высокая эффективность лечения, в особенности в отношении восприятия речи в шумном окружении. В ряде случаев наблюдается синергичный эффект, при котором уровень восприятия речи при комбинированной EAS или PDCI выше, чем суммарный уровень, наблюдаемый только при электрической или акустической стимуляции. Кроме того, новые результаты показывают, что для пациентов с высокими уровнями остаточной слышимости (уровнями PDCI) предпочтительным вариантом является кохлеарная имплантация, преимущества которой, как минимум, сравнимы с преимуществами в отношении пациентов с низшими уровнями остаточной слышимости. Полученные данные достоверно подтверждают целесообразность кохлеарной имплантации у пациентов со стойкой остаточной слышимостью в диапазоне низких частот; вне всяких сомнений, «точку снижения эффективности» еще предстоит определить.
\end{abstract}

Ключевые слова: электро-акустическая стимуляция • кохлеарный имплантат • частичная глухота • кохлеарная имплантация при частичной глухоте • сохранение остроты слуха • слуховые протезы

\section{Background}

Two remarkably effective treatments have been introduced recently for persons with intact or some hearing at low frequencies and little or no hearing at the higher frequencies. The treatments include a deliberately short insertion of a cochlear implant, along with other aspects of the surgery and adjunctive use of certain drugs, to preserve the low-frequency hearing in the implanted ear. Once the patient has recovered from the surgery, the basal end of the cochlea is stimulated electrically via the implant, and the apical end is stimulated in the normal way with acoustic stimuli. This approach was first described by von Ilberg and his team in Frankfurt, Germany, and is called combined electric and acoustic stimulation (combined EAS) of the auditory system [1]. In combined EAS, low-frequency sounds are perceived with the preserved residual hearing, and high-frequency sounds are represented with the cochlear implant.

Partial Deafness Cochlear Implantation (PDCI) is a special case of combined EAS in which the residual hearing at low frequencies is relatively good or even completely intact. PDCI was first described by Skarzynski and his team in Kajetany (near Warsaw), Poland [2,3]. 
Table 1. Information about the subjects in the Research Triangle Institute (RTI) studies. Entries in the Hearing column indicate the presence of residual hearing ipsilateral or contralateral to the cochlear implant.

\begin{tabular}{cllll}
\hline Subject & \multicolumn{1}{c}{ Center } & \multicolumn{1}{c}{ Electrode Array } & Hearing & Language \\
\hline ME6 & Frankfurt & Med-El, $20 \mathrm{~mm}$ & $\begin{array}{l}\text { Ipsilateral (tested), } \\
\text { contralateral }\end{array}$ & German, English \\
\hline SR3 & $\begin{array}{l}\text { Long-standing RTI } \\
\text { subject }\end{array}$ & Ineraid, full & Contralateral & English \\
\hline ME14 & Chapel Hill & Med-El, full & Contralateral & English \\
\hline ME19 & Vienna & Med-El, $20 \mathrm{~mm}$ (compressed array) & $\begin{array}{l}\text { Ipsilateral, } \\
\text { contralateral }\end{array}$ & German \\
\hline ME20 & Frankfurt & Med-El, $20 \mathrm{~mm}$ & $\begin{array}{l}\text { Ipsilateral, } \\
\text { contralateral }\end{array}$ & German \\
\hline ME23 & Warsaw & $\begin{array}{l}\text { Med-El, } 20 \mathrm{~mm} \text { (from the round } \\
\text { window membrane) }\end{array}$ & $\begin{array}{l}\text { Ipsilateral, } \\
\text { contralateral }\end{array}$ & Polish \\
\hline ME26 & Frankfurt & Med-El, $18 \mathrm{~mm}$ (compressed array) & $\begin{array}{l}\text { Ipsilateral } \\
\text { German }\end{array}$ \\
\hline
\end{tabular}

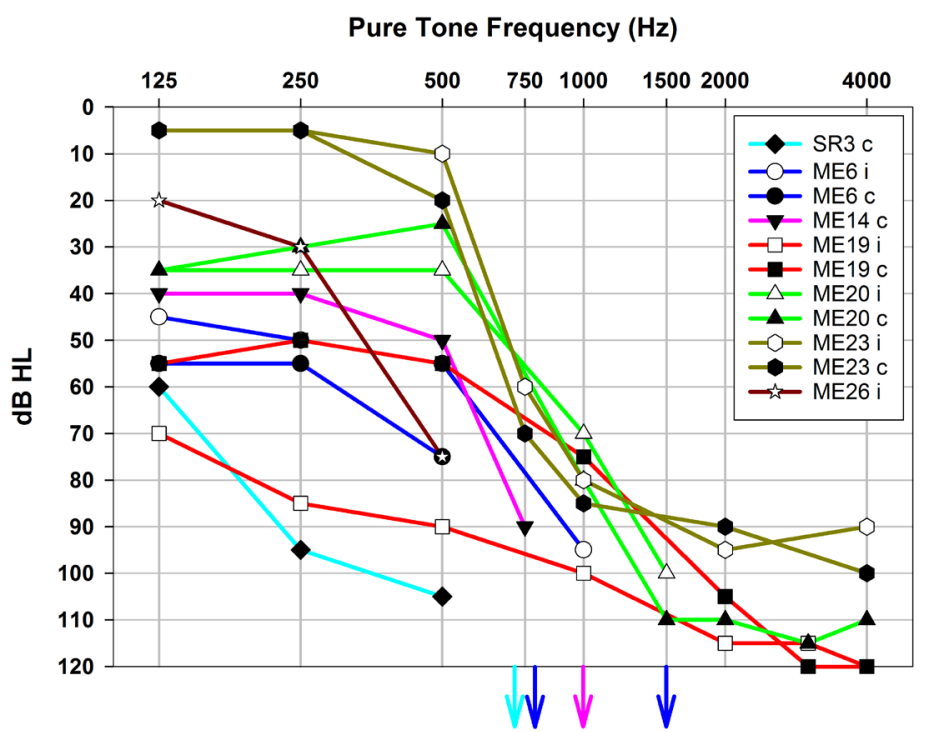

Figure 1. Clinical audiograms for the subjects participating in the Research Triangle Institute (RTI) studies. Open symbols show audiograms for ears ipsilateral to a cochlear implant, and the closed symbols show audiograms for ears contralateral to the implant. The $y$ axis is the Hearing Level $(\mathrm{HL})$ in decibels $(\mathrm{dB})$. The audiograms are the most recent ones measured for each subject prior to her or his participation in the studies and well after her or his implant operation (at least three months after the operation and usually much longer than that).

The main purposes of this paper are to present on behalf of the investigator teams (1) the experiences to date with these two treatments and (2) some new results on the relative benefits of cochlear implantation according to the levels of the residual hearing. The paper is an expanded version of a short paper published previously as a part of a conference proceedings [4]. The information provided here in connection with point 2 above is unique to the present paper, and much further information is provided in connection with point 1 as well.

\section{Combined EAS}

One of the earlier studies to evaluate the efficacy of combined EAS was conducted in our laboratories at the Research Triangle Institute (RTI) in North Carolina, USA, in cooperation with three groups in Europe and one other group in the United States [5-7]. The results from these early studies are representative of results from contemporaneous studies and of results from the many studies conducted since then.
The RTI studies included tests with the first EAS patient in Frankfurt and six additional subjects. Each of the subjects traveled to the RTI Laboratories for her or his participation in the studies. The studies were conducted with the permission and oversight from the RTI Institutional Review Board. Each subject read and signed an informed consent prior to her or his participation. The investigator team included Blake Wilson, Robert Wolford, Dewey Lawson, Reinhold Schatzer, and Stefan Brill from the RTI; Jan Kiefer, Thomas Pfennigdorff, Stefan (Marcel) Pok, Jochen Tillein, and Wolfgang Gstoettner from Frankfurt; Wolf-Dieter Baumgartner from Vienna; Carol Higgins (now Carol Pillsbury) and Harold Pillsbury from Chapel Hill, USA; and Artur Lorens from Warsaw.

Information about the subjects is presented in Table 1 and their post-operative clinical audiograms are presented in Figure 1. Subjects SR3 and ME14 had full insertions on one side of Ineraid and standard Med-El implants, respectively, and the remaining subjects had insertions on one side to 18 or $20 \mathrm{~mm}$ of either the standard Med-El 


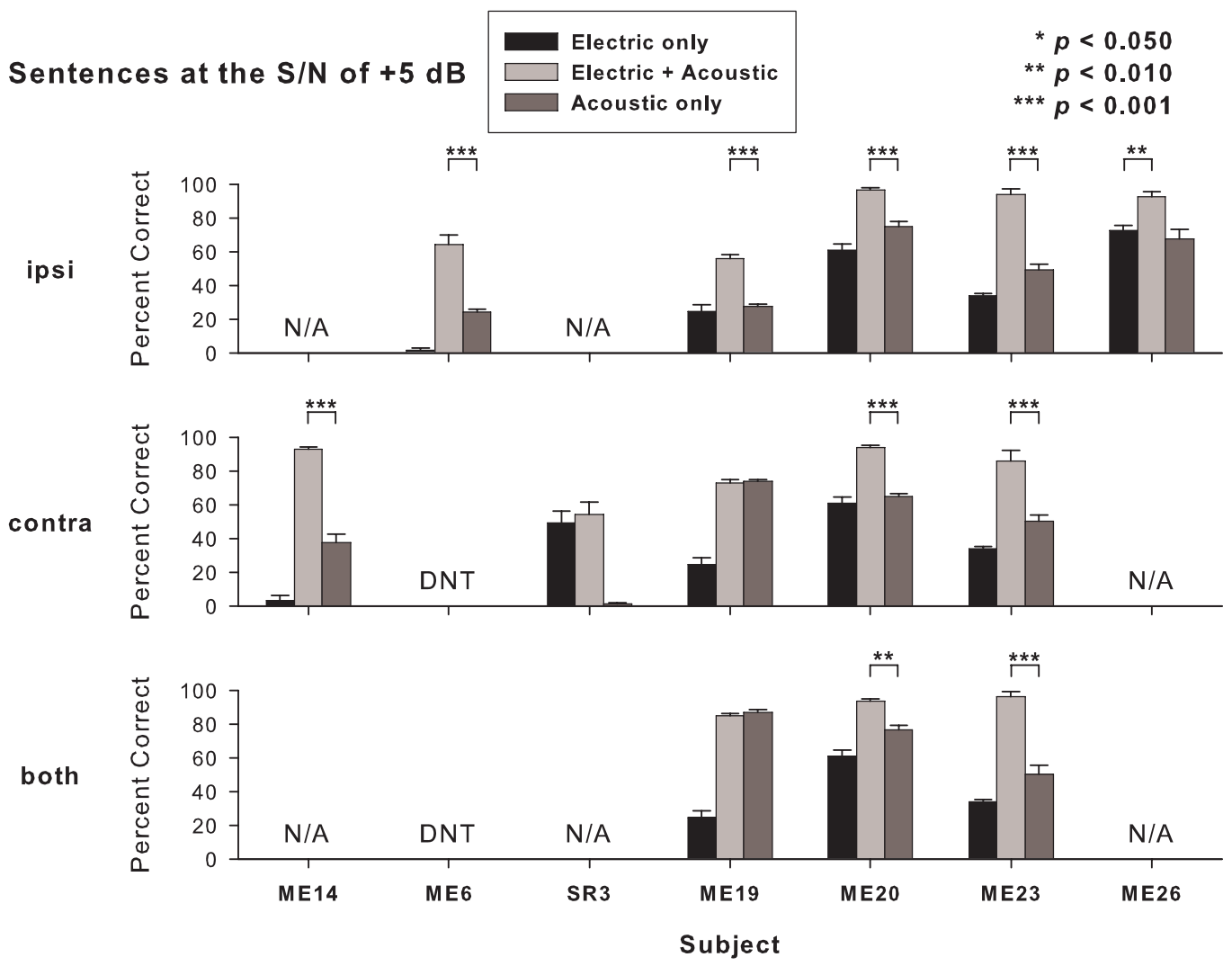

Figure 2. Sentence recognition with the electric stimulation only (black bars, Electric only), acoustic stimulation only (dark gray bars, Acoustic only), and combined electric plus acoustic stimulation (light gray bars, Electric + Acoustic) for the subjects participating in the Research Triangle Institute (RTI) studies. The error bars show standard errors of the means, and the brackets indicate significant differences between the combined-stimulation condition and the next best alternative. Levels of significance are indicated by the asterisks. The sentences were presented in competition with speech-spectrum noise at the speech-to-noise ratio $(\mathrm{S} / \mathrm{N})$ of $+5 \mathrm{~dB}$. The range of frequencies spanned by the bandpass filters in the implant processor was from 350 to $5500 \mathrm{~Hz}$. The range of frequencies present in the acoustic stimuli extended up to $1000 \mathrm{~Hz}$, although not all subjects could perceive frequencies in the upper part of this range; see the audiograms in Figure 1. Some subjects could not be tested for all possible conditions because they did not have useable residual hearing in one ear (denoted by the "N/A" symbols) or not enough time was available to make the measurements (denoted by the "DNT" symbols). Results for delivery of the acoustic stimuli to the same ear as the implant are presented in the top panel (ipsi); results for delivery of the acoustic stimuli to the ear contralateral to the implant are presented in the middle panel (contra); and results for delivery of the acoustic stimuli to both ears are presented in the bottom panel (both).

implant or a compressed array variation of the standard implant, with a closer spacing between adjacent electrode sites. Subjects SR3 and ME14 had no residual hearing in the same ear as the implant, but had at least some residual hearing contralateral to the implanted side. All of the remaining subjects had at least some preserved residual hearing in the implanted cochlea, and four of those five subjects had residual hearing on the contralateral side as well. Tests with the subjects included identification of consonants in an /a/-consonant-/a/ context presented in quiet and in competition with noise, and recognition of sentences in each subject's native language, at various speech-tonoise ratios (S/Ns). Only the most important results are presented here. Further details about the subjects, tests, and test results are presented in Wilson et al. [6].

In Figure 1, the closed symbols show audiograms for ears contralateral to a cochlear implant, and the open symbols show audiograms for ears ipsilateral to an implant. The hearing loss at $1 \mathrm{kHz}$ is $70 \mathrm{~dB}$ or worse for all audiograms. Hearing thresholds are generally better at progressively lower frequencies for each of the audiograms, but the range of thresholds is wide, from nearly normal thresholds at the audiometric frequencies of 125,250 , and $500 \mathrm{~Hz}$ for subject ME23 to substantial losses at those frequencies for subject SR3 (who had residual hearing on the contralateral side only) and subject ME19 on the implanted side.

Results are shown in Figure 2 for the recognition of key words in sentences presented in competition with speechspectrum noise at an $\mathrm{S} / \mathrm{N}$ of $+5 \mathrm{~dB}$. Scores obtained with electric stimulation only are shown with the black bars; scores for acoustic stimulation only are shown with the dark gray bars; and scores for combined EAS are shown with the light gray bars. The error bars show the standard error of the mean for each of the measures. The top 
panel shows results for the acoustic stimuli delivered ipsilateral to the cochlear implant; the middle panel shows results for the acoustic stimuli delivered to the contralateral ear; and the bottom panel shows results for the acoustic stimuli delivered to both ears. The "DNT" notations indicate conditions that were not tested, and the "N/A" notations indicate conditions that were not applicable and could not be tested due to an absence of useful acoustic hearing in one of the ears. In particular, subjects ME14 and SR3 had fully inserted arrays on one side and perhaps as a consequence no residual hearing on that side. Six of the subjects had residual hearing on the contralateral side, although the residual hearing for subject SR3 was poor. Subject ME26 did not have useful residual hearing contralateral to her cochlear implant. In all cases, the acoustic stimuli were generated by first filtering the input sound (speech or speech plus noise) with a $1 \mathrm{kHz}$ lowpass filter and then amplifying the output of the filter linearly such that the loudness of the acoustic stimuli matched or approximated the loudness of the electric stimuli for a subject, which had previously been adjusted to produce a most comfortable loudness. The acoustic stimuli were delivered through circumaural earphones. The range of frequencies analyzed and represented by the implant was from 350 to $5500 \mathrm{~Hz}$.

Spectacular improvements were produced with combined EAS in some cases. Indeed, the scores for the combination are greater than the sum of the scores for electric stimulation only and acoustic stimulation only for three of the subjects (ME14, ME6, and ME23). Findings like these have been called "synergistic effects" of combined EAS (e.g., [8]).

Results for other subjects also demonstrate remarkable improvements with the combination, either for the acoustic stimuli delivered to one or both ears. As shown, the improvements are highly significant $(p<0.01$ or better) for six of the seven tested subjects. The one subject who did not show a significant improvement had only a modicum of residual hearing in her acoustically sensitive ear (subject SR3). Her scores were not increased significantly with the combination, but they were not harmed by it either.

For some of the subjects with residual hearing on both sides, combined EAS was equally effective with the acoustic stimuli delivered to either ear (subjects ME20 and ME23). In addition, the effectiveness was at least maintained with delivery of the acoustic stimuli to both ears.

Delivery of the acoustic stimuli to the ear contralateral to a cochlear implant is sometimes called "bimodal stimulation" [9-11], and delivery of the acoustic stimuli to both ears is sometimes called a "best aided" condition. Delivery of the acoustic stimuli to the ear ipsilateral to a cochlear implant has been described as combined EAS, as previously noted. All are variants of combined electric and acoustic stimulation of the auditory system, and one or more of the variants may be effective for an individual patient depending on his or her patterns of hearing loss within and between the two sides.

An informative taxonomy of conditions and treatments is presented in Skarzynski and Lorens [12]. Those authors describe different degrees of hearing loss for each of the two ears in terms of audiograms and recognition of monosyllabic words. Depending on the losses for each side and between the sides, different treatment options are suggested that include the options mentioned above plus (1) acoustic stimulation only for borderline cases in which the residual hearing is substantial in at least one of the ears, and (2) the PDCI for cases in which the residual hearing is at least good for frequencies at and below $500 \mathrm{~Hz}$ but poor or absent at higher frequencies. (This latter treatment is called an "electric complement" treatment in the taxonomy developed by Skarzynski and Lorens.) Additional information about the PDCI treatment is provided later in this present paper.

What is not shown in Figure 2 is the likely advantage of residual hearing on both sides - and acoustic stimulation on both sides - for realistic environments with multiple sources of sound at different locations. The data in Figure 2 were collected with both the primary speech signal and the interfering noise presented from in front of the subjects. Thus, no "spatial separation" advantage is demonstrated in the bottom panel of the figure, for the acoustic stimuli delivered to both sides. In contrast, when the primary and interfering sounds are presented from different locations, scores for combined electric and acoustic stimulation with the acoustic stimuli delivered to both ears are significantly better than the scores for the combination with the acoustic stimuli delivered to one of the ears only [13]. This advantage is a major incentive to preserve any residual hearing in an implanted cochlea even for cases in which substantial residual hearing is present on the contralateral side.

A question that arises in the application of combined EAS is how to choose the frequency ranges represented by each mode of stimulation. For the acoustic stimuli, one might suggest that all frequencies within the range of the residual hearing should be included. Certainly, for any overlapping frequencies between the two modes of stimulation, acoustic stimuli would be expected to provide a better representation than electric stimuli.

In addition, Baer et al. [14] have shown that amplification at frequencies up to one octave beyond the highest frequency with a good sensitivity to acoustic stimuli can be beneficial for persons with high-frequency hearing losses. Thus, alternative prescriptions for the acoustic stimuli would be either to present (1) all frequencies within the range of the residual hearing or (2) those frequencies plus the frequencies in the range one octave beyond the highest frequency with a good sensitivity to acoustic stimuli.

For the electric stimuli, one might suggest that all frequencies normally represented by the implant (e.g., 350-5500 $\mathrm{Hz}$ or higher) should be represented for combined EAS as well. This choice would provide "overlapping" representations of frequencies between the two modes of stimulation for many patients, e.g., the acoustic stimuli might represent frequencies up to $1000 \mathrm{~Hz}$ or thereabouts, and the implant might represent frequencies from 350 to $5500 \mathrm{~Hz}$ or higher.

Two alternatives to the overlapping representations would be to (1) provide contiguous representations, with the frequency range represented by the implant beginning where 
Consonants in quiet

\section{Consonants at the $S / N$ of $+5 d B$}

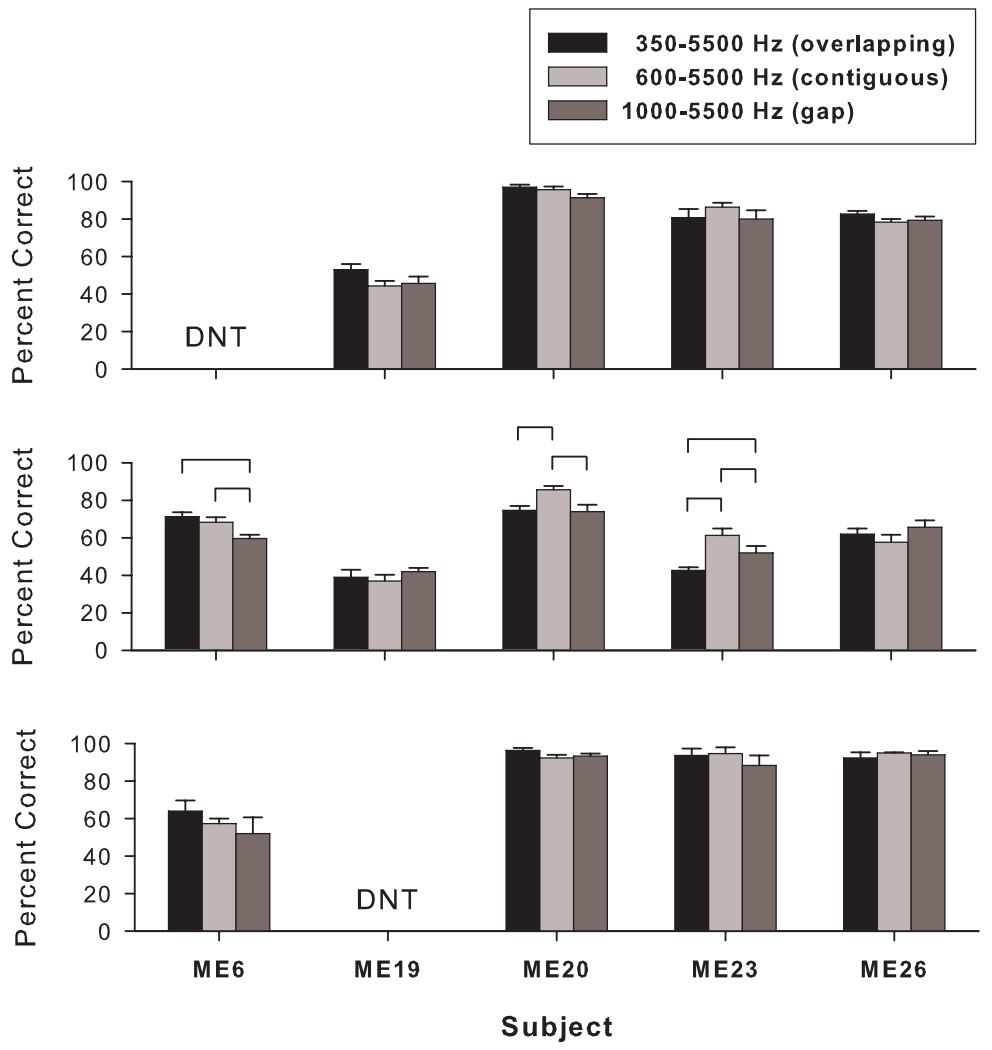

Figure 3. Identification of consonants in quiet and in noise at the speech-to-noise ratio $(\mathrm{S} / \mathrm{N})$ of $+5 \mathrm{~dB}$, and recognition of sentences at the $\mathrm{S} / \mathrm{N}$ of $+5 \mathrm{~dB}$, for five of the subjects participating in the Research Triangle Institute (RTI) studies. Electric and acoustic stimuli were combined with three different ranges of frequencies spanned by the bandpass filters in the implant processor, with the number of processing channels and corresponding sites of stimulation in the cochlea held constant. The range of frequencies present in the acoustic stimuli extended up to $500 \mathrm{~Hz}$. The black bars show the scores for the combined stimulation with the implant representing frequencies from 350 to $5500 \mathrm{~Hz}$; the light gray bars show the scores for the combined stimulation with the implant representing frequencies from 600 to $5500 \mathrm{~Hz}$; and the dark gray bars show the scores for the combined stimulation with the implant representing frequencies from 1000 to $5500 \mathrm{~Hz}$. These conditions correspond to overlapping, contiguous, and discontinuous (i.e., with a gap) representations of frequencies with the two modes of stimulation. Some conditions were not tested due to lack of time and are denoted with the "DNT" symbols. The error bars show standard errors of the means, and the brackets indicate significant differences $(p<0.05)$ between conditions for a given subject and test.

the range represented by the acoustic stimuli ends, or (2) introduce a gap in the representations, with the frequency range for the implant beginning at a higher frequency than the highest frequency represented by the acoustic stimuli. The contiguous representations might eliminate or at least reduce any interference between modes of stimulation that could occur with the overlapping representations, and the gap in the representations might help assure that any interference would be prevented. (Interference could result, for example, from mutual masking between electric and acoustic stimuli representing the same frequencies or acting at the same or nearby places along the cochlear partition.) A possible downside in introducing a gap is that some frequencies would not be represented with either mode of stimulation. Finally, overlapping representations might well be constructive in that information provided by either mode of stimulation could reinforce or complement the other.

Data from the RTI studies that bear on the question are presented in Figure 3. Identification of consonants presented in competition with speech-spectrum noise at an $\mathrm{S} / \mathrm{N}$ of +5
$\mathrm{dB}$ was evaluated in tests with five subjects, and identification of the consonants in quiet was evaluated in tests with four of those subjects. Recognition of sentences in noise at the same $\mathrm{S} / \mathrm{N}$ was evaluated in tests with another four of the five subjects. The acoustic stimuli delivered for all tests and subjects was lowpass filtered at $500 \mathrm{~Hz}$, to provide a consistent representation of frequencies with those stimuli that would be more immune to differences in residual hearing for the subjects than the $1000 \mathrm{~Hz}$ setting. The frequency range represented by the implant (or, more specifically, by the overall frequency range of the bank of bandpass filters in the implant processor) was varied to include 350-5500 Hz, 600-5500 Hz, and 1000-5500 Hz. The first two of these conditions corresponded to overlapping and contiguous representations, respectively. The third condition corresponded to a gap in the representations. Both the electric and the acoustic stimuli were delivered to the same ear.

The results show a broad equivalence of the scores across the conditions. No significant differences were found among the conditions for identification of consonants in 
quiet (top panel) or for recognition of sentences presented in competition with noise (bottom panel). For consonants presented in competition with the noise, two of the subjects (ME20 and ME23) achieved significantly higher scores with contiguous representations compared with the two alternatives. Another subject (ME6) achieved significantly higher scores with the overlapping and contiguous representations compared with the gap condition.

In all, the results for these subjects and speech reception tests do not show much sensitivity to the manipulation in the frequency range represented by the cochlear implant. Some sensitivity was demonstrated for one of the tests (consonants at an $\mathrm{S} / \mathrm{N}$ of $+5 \mathrm{~dB}$ ), which varied among subjects and was not present for others. The overlapping or contiguous representations appear to be safe choices for combined EAS, and results might be improved somewhat for some patients by comparing the two choices before making a final decision.

These results are generally consistent with subsequent findings, i.e., overlapping $[15,16]$ or contiguous [17] representations are best for most or all patients. Zhang et al. [16] argue that the default choice should be the overlapping representations, as the data from their study strongly support this recommendation. In addition, all but one of the 13 subjects in the study by Kiefer et al. [15] preferred and performed best with the overlapping representations. (The exceptional subject preferred and performed best with the contiguous representations.)

A further noteworthy aspect of the results from the RTI studies is illustrated in Figure 4. Each of the panels in the figure shows results for one of the subjects across the range of tested S/Ns for that subject's best combination of electric and acoustic stimuli. For subjects SR3 and ME14 this best combination included delivery of the acoustic stimuli to the side contralateral to the cochlear implant and the standard full range of frequencies represented by the implant. For the remaining subjects the best combination included delivery of the acoustic stimuli either to the side ipsilateral to the implant or to both sides. In addition, the range of frequencies represented by the implant varied across these latter subjects to produce the best results; the choice for most of the subjects was the standard full range, i.e., overlapping representations between the electric and acoustic modes of stimulation. The acoustic stimuli were generated and presented in the same way as described previously in connection with Figure 2. In addition, the bar codes and labeling conventions in Figure 4 are the same as those in Figure 2. The error bars in both figures show the standard errors of the means.

Results for the best combinations for each subject are presented in Figure 4. Results for other combinations and additional S/Ns are presented in Wilson et al. [6].

The $\mathrm{S} / \mathrm{Ns}$ included in Figure 4 ranged from quiet to the highly adverse $\mathrm{S} / \mathrm{N}$ of $-5 \mathrm{~dB}$. Results for the $\mathrm{S} / \mathrm{N}$ of $+5 \mathrm{~dB}$ are highlighted in the figure because all subjects were tested at this $\mathrm{S} / \mathrm{N}$ and because $+5 \mathrm{~dB}$ approximates the $\mathrm{S} / \mathrm{Ns}$ encountered in many typical acoustic environments such as workplaces or cafeterias.
Scores for combined EAS are significantly higher than the scores for electric stimulation only or acoustic stimulation only for five of the seven subjects at the $\mathrm{S} / \mathrm{N}$ of $+5 \mathrm{~dB}$. In contrast, the results presented in Figure 2 show a significant benefit of the combination for six of the subjects. The difference is due to the selection of the best combination for each subject in Figure 4. In particular, acoustic stimulation of both ears produced the highest combination scores for subject ME19 and yet that choice also produced an exceptionally high score for acoustic stimulation only, a score that is just as high (and near the ceiling of 100 percent correct) as the combination score. The advantage of the combination shown for this subject in Figure 2 is for acoustic stimuli delivered to the ear ipsilateral to the cochlear implant and not to both ears.

Depending on the conditions for stimulation, either five or six of the seven subjects in the RTI studies have significantly higher scores with combined EAS than with electric stimulation only or acoustic stimulation only. In some cases, a benefit of the combination is observed even when the score for electric stimulation only or for acoustic stimulation only is zero or close to zero. Such instances are seen Figure 4 for subject ME14 at the $\mathrm{S} / \mathrm{N}$ of $+5 \mathrm{~dB}$; subject ME6 also at $+5 \mathrm{~dB}$; subject SR3 at $+10 \mathrm{~dB}$; ME20 at $-5 \mathrm{~dB}$; and ME23 at $0 \mathrm{~dB}$.

The results presented in Figure 4 also demonstrate a remarkable immunity to noise interference that is conferred with the combination. For example, the results for subject ME20 show a precipitous decline in scores for the electric stimulation only conditions, across the $\mathrm{S} / \mathrm{Ns}$ ranging from $+5 \mathrm{~dB}$ to $-5 \mathrm{~dB}$. In contrast, scores for the combination remain high for this subject across the same range of $\mathrm{S} / \mathrm{Ns}$. Indeed, the score for the combination at the $\mathrm{S} / \mathrm{N}$ of $-5 \mathrm{~dB}$ is 69 percent correct, which is consistent with good speech communication even at this highly adverse $\mathrm{S} / \mathrm{N}$ and which approaches the performance of subjects with normal hearing in listening to the sentences at the same $\mathrm{S} / \mathrm{N}$.

The precipitous decline in scores across $\mathrm{S} / \mathrm{Ns}$ seen for ME20 and other subjects (ME14, ME19, ME23, and ME26) for electric stimulation only is typical of the broader experience with cochlear implants. In particular, the speech reception performance of implant patients is highly sensitive to noise interference and indeed implant patients are not usually tested at $\mathrm{S} / \mathrm{Ns}$ more adverse than $+10 \mathrm{~dB}$ because performance at the worse $\mathrm{S} / \mathrm{Ns}$ is often very poor or zero. The addition of the acoustic stimulus provides a major advantage.

Conclusions from the RTI studies are that (1) the results show a highly beneficial effect of combinations of electrically plus acoustically elicited hearing for most tested subjects; (2) the measured immunity to noise interference is remarkable for some subjects with the combinations; (3) benefits are present even for subjects with low levels of residual hearing; (4) benefits are present for some subjects even when the score for electric stimulation only or acoustic stimulation only is zero or close to it; and (5) an increase in the lower limit of the range of frequencies represented by the implant can be helpful for some subjects but most subjects will perform well or at their best with the full standard range of frequencies. These conclusions also are consistent with the findings from many 


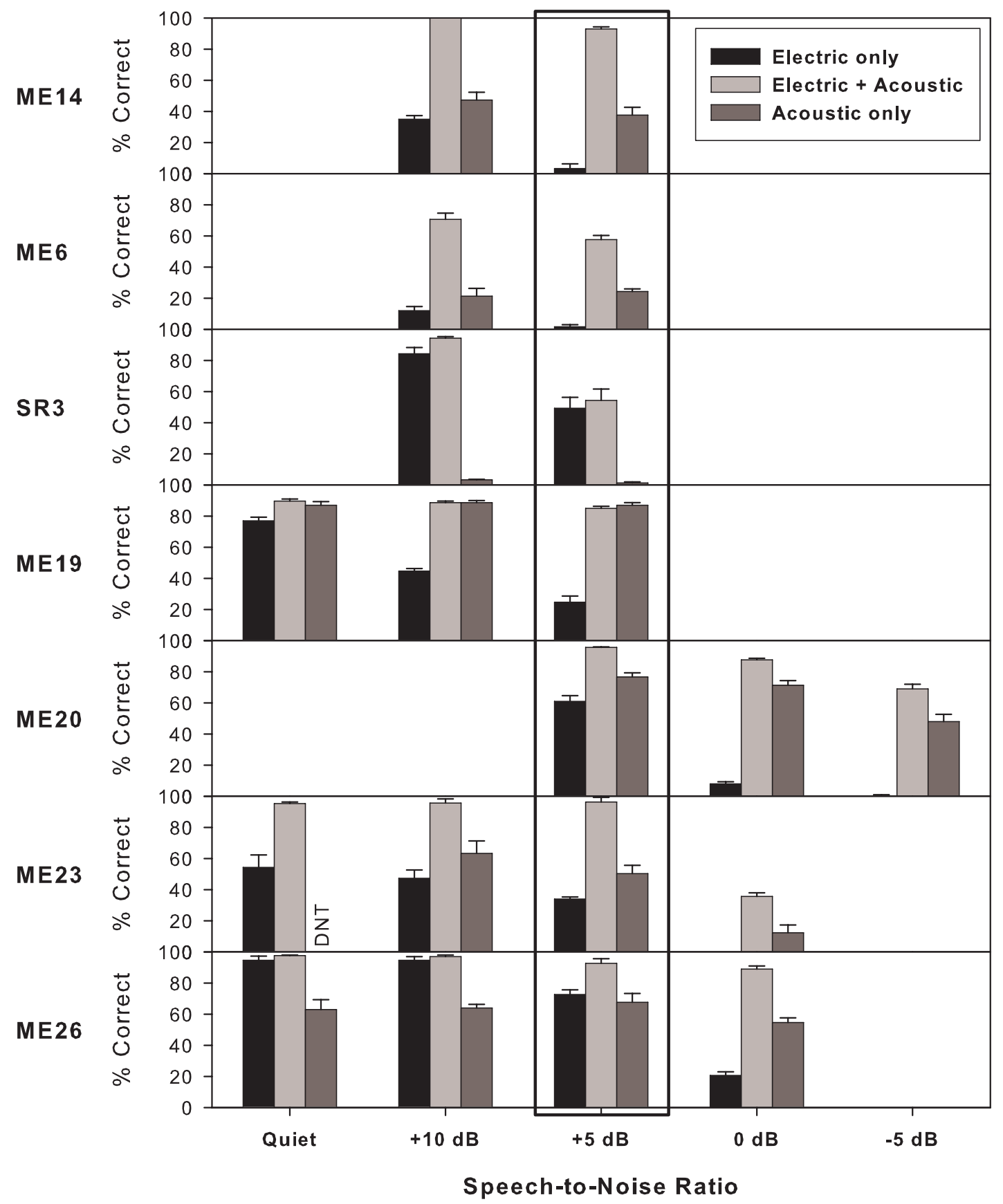

Figure 4. Sentence recognition across ranges of speech-to-noise ratios (S/Ns) for the subjects participating in the Research Triangle Institute (RTI) studies. The black bars show the scores obtained with electric stimulation only (Electric only); the dark gray bars show the scores for acoustic stimulation only (Acoustic only); and the light gray bars show the scores for combined electric and acoustic stimulation (Electric + Acoustic). The error bars show standard errors of the means. As described in the text, optimized combinations of electric and acoustic stimulation were used for each subject.

other studies of combined EAS with depths of electrode insertion approximating $20 \mathrm{~mm}$ or angles of electrode insertion approximating 360 degrees. Significant benefits of combined EAS have been observed as well for shallower depths or smaller angles, e.g., insertion depths of $10 \mathrm{~mm}$ $[18,19], 16 \mathrm{~mm}$ [20], or 17-19 $\mathrm{mm}$ [21]. No data are available at present comparing in the same studies and with the same measures the relative efficacies of the different depths, either for speech reception or for preservation of hearing in the implanted cochlea.

\section{PDCI}

As mentioned previously, PDCI is a special case of combined EAS in which the level of residual hearing is relatively good. An example of PDCI-level hearing can be seen 
Pure Tone Frequency $(\mathrm{Hz})$
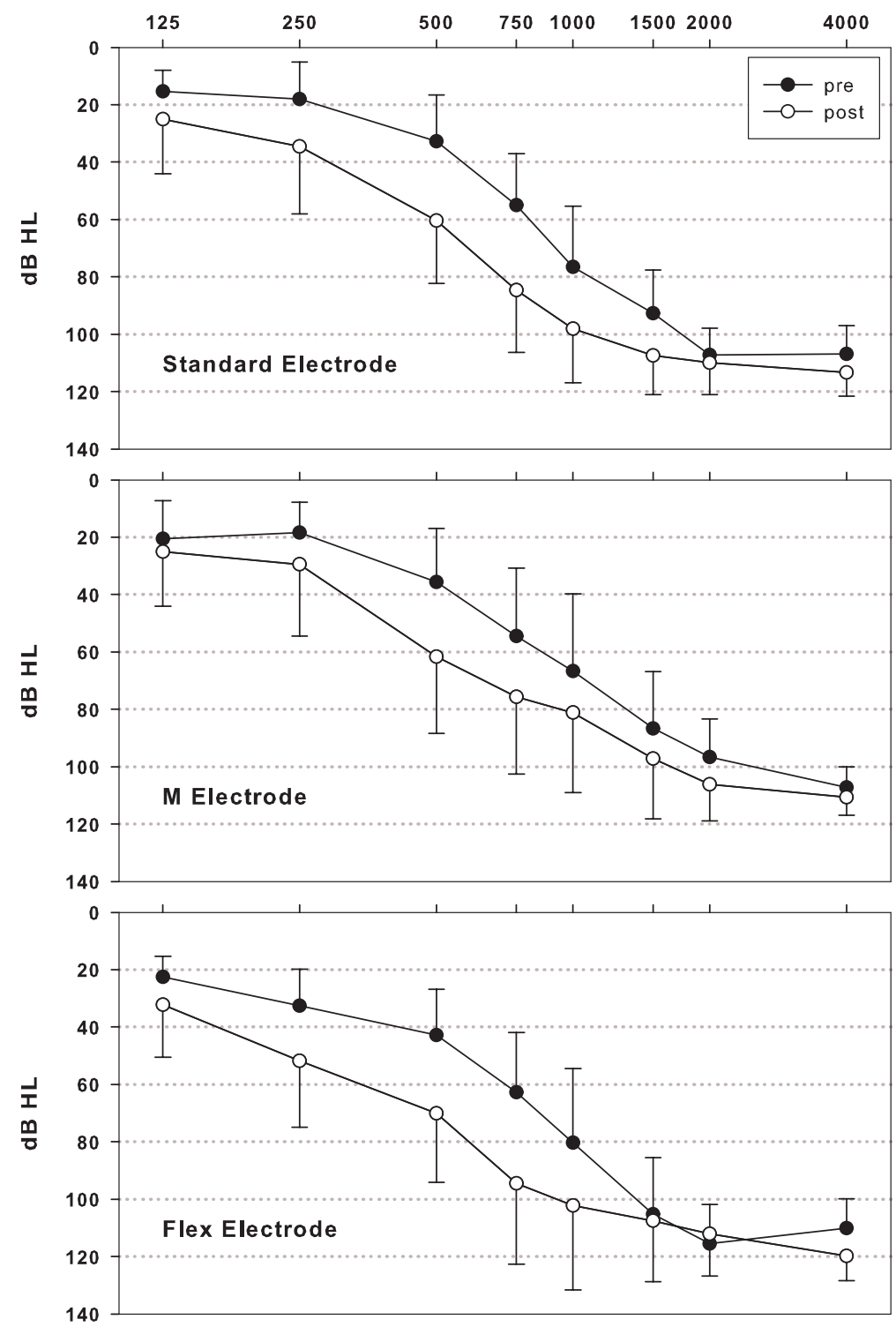

Figure 5. Hearing preservation for three types of electrodes, all inserted through an incision in the round window membrane and to a depth of approximately $20 \mathrm{~mm}$ from the membrane. The averages of the audiograms for all subjects implanted with each type of electrode are shown. Pre-operative Hearing Levels (HLs) in decibels (dB) are shown with the closed symbols and the post-operative HLs are shown with the open symbols. The error bars show standard deviations. Skarzynski et al. [3]) in the audiograms for subject ME23 in Figure 1 (hexagon symbols). Her hearing in either ear is $20 \mathrm{~dB}$ HL or better at the audiometric frequencies of 125,250 , and $500 \mathrm{~Hz}$.

Although such hearing is good at the low frequencies, it is insufficient for adequate speech communication in everyday listening situations. Thus, Skarzynski and his team have extended the concept of combined EAS to include these patients.

The experience with PDCI as of 2009 is summarized in a report by the Warsaw team [3]. The described studies included 28 subjects, 18 adults and 10 children, who were diagnosed with partial deafness and received a partial insertion of the standard Med-El array $(n=15)$, a full insertion of the Med-El "M" (or "Medium") array ( $n=10)$, or a partial insertion of the Med-El "Flex" (or "Flex ${ }^{\text {SOFT") }}$ array $(\mathrm{n}=3)$, all to approximately $20 \mathrm{~mm}$ from the round window membrane.
A special surgical approach was used for these implant operations, that included insertion of the electrode array through the round window as opposed to making a cochleostomy and inserting the array through that fenestration. Five additional steps in the approach were all aimed at preservation of residual hearing in the implanted ear.

Hearing preservation results for the three different types of electrodes and for all 28 subjects are presented in Figure 5. At least some hearing was preserved and found to be stable over 1-4 years post implant for 84 percent of the subjects. Hearing within $10 \mathrm{~dB}$ of the pre-operative thresholds was maintained in 13 of the subjects. No significant differences in preservation were found among partial insertion of the standard array (top panel in Figure 5), full insertion of the " $M$ " array (middle panel), or partial insertion of the Flex array (bottom panel), all to $20 \mathrm{~mm}$. The reductions in hearing sensitivity following the operation were small for many of the subjects and the remaining hearing for 

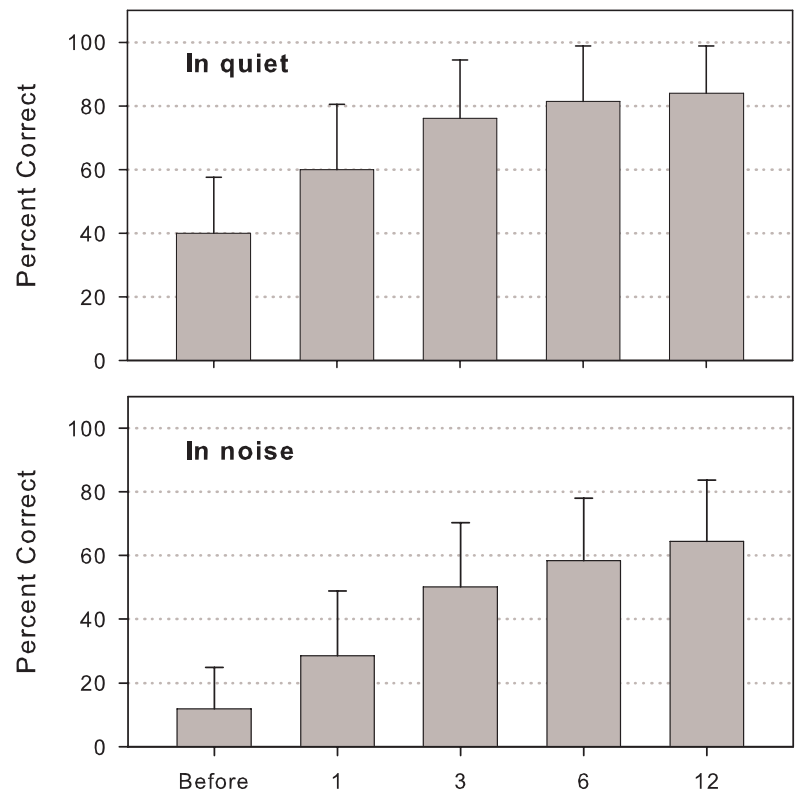

Measurement Interval (numerical values in months)
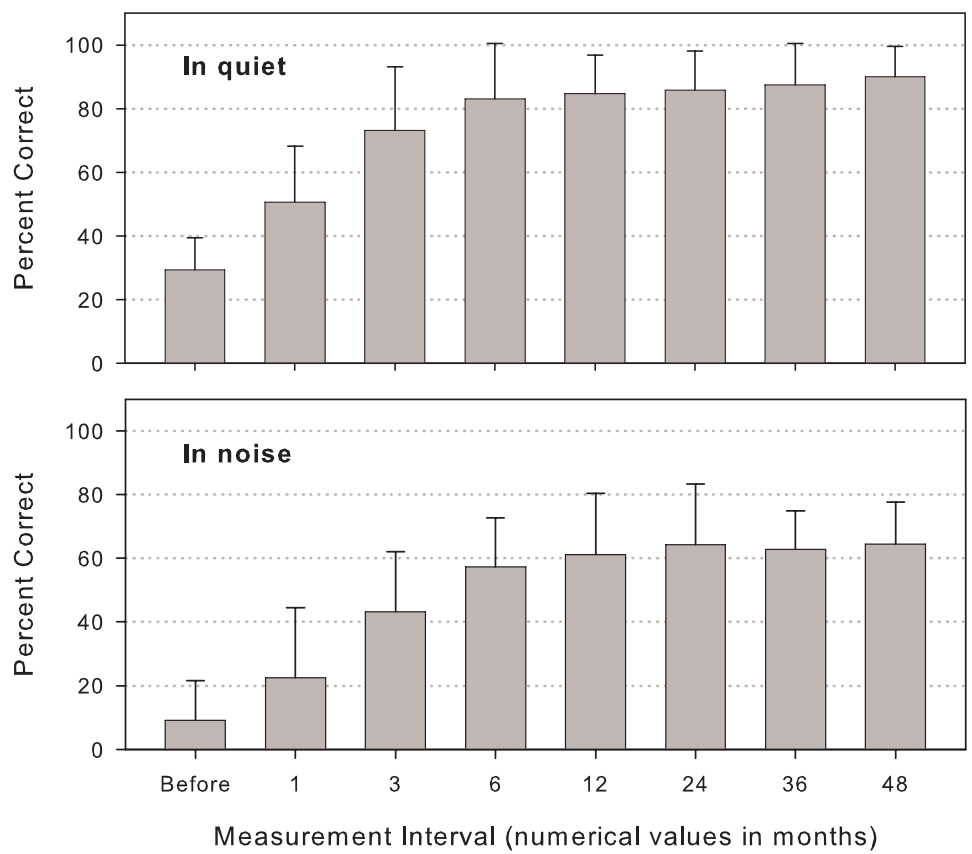

Figure 6. Recognition of the Pruszewicz monosyllabic words by 25 subjects in the 2009 study of Skarzynski et al. [3]. The top panel shows the mean scores for the words presented in quiet, and the bottom panel shows the scores for the words presented in competition with speech-spectrum noise at the speech-to-noise ratio of $+10 \mathrm{~dB}$. The times given for the measurement interval are referenced to the time of the implant operation. The error bars show standard deviations. Skarzynski et al. [3]

Figure 7. Recognition of the Pruszewicz monosyllabic words by the eight subjects in the 2009 study of Skarzynski et al. [3], who had accrued at least 48 months of experience with combined electric and acoustic stimulation. The organization of the present figure is the same as that in Figure 6. Skarzynski et al. [3] the great majority of the subjects was useful, as demonstrated in tests of speech reception using combined EAS.

Evaluation of the PDCI treatment included recognition by the subjects of Polish monosyllabic words (from the Pruszewicz Monosyllabic Word Test) presented either in quiet or in competition with speech-spectrum noise at the $\mathrm{S} / \mathrm{N}$ of $+10 \mathrm{~dB}$. Recordings of the words or the words plus noise were presented via a loudspeaker at $60 \mathrm{~dB}$ SPL in an acoustically isolated and sound treated room. The subject for each test was located in the room one meter in front of the loudspeaker. The Pruszewicz Test corpus includes 20 lists of 20 words each. Three lists were used for each $\mathrm{S} / \mathrm{N}$ condition (quiet and $+10 \mathrm{~dB}$ ) for each subject and at each measurement interval to reduce the variance in the measures. Scores for each test session were calculated as the means of the scores from the three lists. The lists were randomized among the $\mathrm{S} / \mathrm{N}$ conditions, subjects, and intervals. The intervals included a pre-operative session and sessions at $1,3,6$, and 12 months post implant.

Results from the tests are presented in Figure 6. The scores from 25 of the 28 subjects are included in the figure, as the tests were too difficult to complete for three among the ten children.

No statistically significant difference was found between the results for the seven tested children and the 18 adults, so the data for the two groups were pooled for the final analyses. Figure 6 presents the pooled results. Means and 
standard deviations are shown. Pairwise comparisons with the Tukey test following a significant Repeated Measures ANOVA indicate that: (1) for quiet, the differences in the means between the pre-operative and 1-month intervals, the 1- and 3-month intervals, the 1- and 6-month intervals, and the 3- and 12-month intervals are all significant; and (2) for speech presented in competition with noise, the same pattern of significant differences is found. Significant increases in the mean scores are observed out to the maximum tested interval of 12 months post implant.

Eight of the subjects had accrued 48 months of experience at the time of the 2009 publication by Skarzynski et al., and their mean scores are presented in Figure 7 for the quiet and $+10 \mathrm{~dB} S / \mathrm{N}$ conditions. For the quiet condition, the scores increased from 29.4 percent correct before the operation to 83.1 percent correct six months after the operation. Performance increased more gradually after that, with mean scores of $84.8,85.9,87.5$, and 90.0 percent correct for the 12-, 24-, 36-, and 48-month intervals, respectively. The difference in the mean scores between the 6- and 48-month intervals is not significant. Thus, rapid (and highly significant) increases in the mean scores are found up to six months following the operation, and the scores plateau after that.

The mean scores for recognition of the words in noise by these same eight subjects increased out to 24 months post implant, i.e., the differences in the means between the preoperative and 3-month intervals, the 1- and 3-month intervals, the 1 - and 6-month intervals, and the 3 - and 24-month intervals are all significant. The mean scores at and beyond the 24-month interval are nearly identical and not significantly different from one another. Thus, performance increases monotonically up to 6 months for recognition of the words in quiet, and up to 24 months for recognition of the words presented in competition with noise. Performance remains unchanged out to the tested maximum interval of 48 months following these initial increases.

Conclusions from the Warsaw studies are that: (1) the results show a highly beneficial effect of combinations of electrically plus acoustically elicited hearing for subjects with relatively high levels of residual hearing; (2) children can benefit from PDCI as much as adults; (3) residual hearing can be preserved in an implanted cochlea for the great majority of patients, using a six-step procedure that includes careful insertion of the electrode array through the (incised) round window membrane and a depth of insertion from the membrane that approximates $20 \mathrm{~mm}$; and (4) results for the first eight subjects in the series (who had accrued considerable experience with PDCI) demonstrate highly stable performance out to the tested limit of four years.

\section{Dependence of outcomes on the levels of residual hearing}

A retrospective chart study is underway at the International Center of Hearing and Speech (ICHS) in Kajetany, Poland, to (1) identify in a large population pre-operative factors that may be associated with outcomes for patients using a cochlear implant in conjunction with residual (usually low frequency) hearing, and (2) determine the relative benefits of cochlear implantation according to the levels of the remaining hearing. This study is being led by Artur Lorens and the project team includes Blake Wilson, Anna Piotrowska, and Henryk Skarzynski. Preliminary results indicating benefits according to the amount of residual hearing are presented in the remainder of this section, and the full and final results from the study will be presented in a separate publication after the study is completed.

The charts for 159 patients were culled from the archives of charts at the ICHS. These records were from patients implanted at the Center from mid December 2002 to late June 2007. The only criteria for selection were measureable residual hearing and use of that hearing in conjunction with a unilateral cochlear implant following the operation. Residual hearing was characterized for each ear of each patient using the following rules involving the hearing level (HL) at $500 \mathrm{~Hz}$ and the pure tone average (PTA) of HLs at 125, 250, and $500 \mathrm{~Hz}$ :

- PDCI-level hearing: $55 \mathrm{~dB}$ HL or better at $500 \mathrm{~Hz}$, or PTA $\leq 45 \mathrm{~dB}$ HL

- EAS-level hearing: $80 \mathrm{~dB}$ HL or better at $500 \mathrm{~Hz}$, or PTA $\leq 70 \mathrm{~dB} H \mathrm{HL}$

- Neither: Worse than $80 \mathrm{~dB} \mathrm{HL}$ at $500 \mathrm{~Hz}$ and PTA $>70 \mathrm{~dB}$ HL

Among the 159 patients, 43 had PDCI-level hearing in at least one ear, 62 had hearing up to the EAS level in at least one ear, and the residual hearing of the remaining 54 patients did not attain EAS status in either ear. Thus, a wide distribution of residual hearing was represented in this (large) population of subjects.

The outcome measures for each of the subjects were the same as those described in the prior section on PDCI, i.e., recognition of the Pruszewicz monosyllabic words in quiet and in noise at the $\mathrm{S} / \mathrm{N}$ of $+10 \mathrm{~dB}$. The listening conditions included recognition of the words with the residual hearing only (RH only) and the cochlear implant plus the residual hearing $(\mathrm{CI}+\mathrm{RH})$. For most subjects, the residual hearing was aided with a well-fitted hearing aid, for either or both ears. The remaining subjects did not need and did not use a hearing aid, as their residual hearing was good enough for sufficient audibility at the low frequencies without an aid. (All of these subjects had PDCI-level hearing in at least one ear.) All subjects had had substantial experience with their implants (and with combined acoustic plus electric stimulation) at the time of the reported measures. For most of the subjects, measures at multiple intervals were available and these measures were averaged for each test and subject to indicate outcomes. For the relatively few subjects with single measures only, those single measures were used to indicate the outcomes.

The means and standard deviations of the outcome measures according to the category of hearing loss are presented in Figure 8. Results for the subjects with PDCI-level hearing in at least one ear are shown with the black bars; results for the subjects whose best hearing is at the EAS level in at least one ear are shown with the light gray bars; and results for the subjects who do not have even EASlevel hearing in either ear are shown with the dark gray bars. The left two sets of bars show the means and standard deviations of the outcome measures for the words 


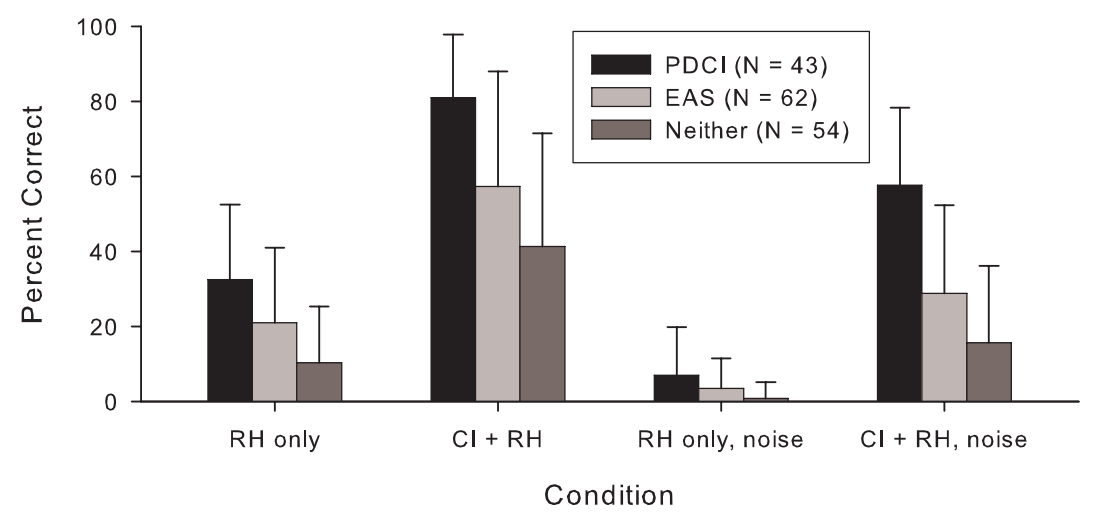

Figure 8. Recognition of the Pruszewicz monosyllabic words by 159 subjects previously implanted at the International Center of Hearing and Speech in Kajetany, Poland, and with at least some residual hearing either ipsilateral or contralateral to the implanted ear, or in both ears. Subjects are divided into groups according to their best residual hearing in either ear. The $43 \mathrm{PDCl}$ subjects had thresholds of $55 \mathrm{~dB}$ Hearing Level $(\mathrm{HL})$ or better at the audiometric frequency of $500 \mathrm{~Hz}$, or a pure tone average (PTA) of HLs at 125,250 , and $500 \mathrm{~Hz}$ of $45 \mathrm{~dB} \mathrm{HL}$ or better. The 62 EAS subjects had thresholds of $80 \mathrm{~dB} \mathrm{HL}$ or better at $500 \mathrm{~Hz}$ or a PTA of $70 \mathrm{~dB} \mathrm{HL}$ or better. The 54 remaining subjects (the "Neither" category in the figure legend) did not attain either of the EAS criteria for either ear, i.e., their thresholds at $500 \mathrm{~Hz}$ were worse than $80 \mathrm{~dB} \mathrm{HL}$ and their PTAs were worse than $70 \mathrm{~dB} \mathrm{HL}$ for both ears. The conditions for the tests included recognition of the words in quiet with the residual hearing only ( $\mathrm{RH}$ only); recognition of the words in quiet with the cochlear implant plus the residual hearing $(\mathrm{Cl}+\mathrm{RH})$; recognition of the words presented in competition with speech-spectrum noise at the speech-to-noise ratio of $+10 \mathrm{~dB}$ with the residual hearing only ( $\mathrm{RH}$ only, noise); and recognition of the words in the noise using the cochlear implant plus the residual hearing $(\mathrm{Cl}+\mathrm{RH}$, noise). Many of the subjects were tested at multiple intervals and the averages of their scores were used for the calculations of mean scores across subjects. The error bars show standard deviations.

presented in quiet, and the right two sets of bars show the outcome measures for the words presented in competition with noise.

Figure 8 indicates large benefits of combined EAS for all three categories of hearing loss, for the words presented in quiet or in competition with noise. The differences between like bars (same category of residual hearing) in the left two sets of bars, and between like bars in the right two sets of bars, are all significant at the $p<0.001$ level using paired $t$ tests.

A surprising aspect of these results is that patients with high levels of residual hearing (the PDCI levels) receive benefits from cochlear implantation that are at least as great as the benefits received by patients with lower levels of residual hearing. In addition, the highest scores are obtained by the patients with the PDCI levels of hearing. These findings are counter to the conventional wisdom that patients with such good residual hearing can be harmed by cochlear implantation and suggest that the criteria for implant candidacy should be relaxed further so that many more patients can benefit from the procedure (also see [22]).

This concept to broaden candidacy criteria for cochlear implants is further supported by the data presented in Figure 9, which shows the individual scores for the $43 \mathrm{sub}-$ jects with PDCI-level hearing in at least one ear. Only two of the subjects (subjects 25 and 33) have the same or similar scores between the RH only and CI + RH conditions, for either the words presented in quiet (top panel of Figure 9, subject 33) or in noise (bottom panel, subjects 25 and 33). The scores for the 41 remaining subjects all demonstrate improvements with the addition of the cochlear implant. (The scores for subject 25 also demonstrate an improvement for the quiet condition.) Many of the increases are large, and the full magnitude of some of the increases may be masked by likely ceiling effects, especially for the words presented in quiet. (For the words presented in noise, 27 of the subjects move from zero percent correct with their residual hearing only, to 32 percent correct or higher with the addition of the cochlear implant; one of the subjects moves from zero percent correct to 88 percent correct, subject 42.) Most of the subjects benefitted greatly from cochlear implantation and no subject was harmed by it.

Conclusions from the "relative benefits" study to date are that: (1) patients with high levels of residual hearing (PDCI levels) receive benefits from cochlear implantation that are at least as great as the benefits received by patients with lower levels of residual hearing; (2) the highest scores are obtained by the patients with PDCI levels of hearing; (3) no patient was harmed by cochlear implantation, and the great majority of patients benefitted greatly, including the patients with PDCI levels of hearing; and (4) these findings strongly support the concept of providing cochlear implants for persons with substantial residual hearing; indeed, a "point of diminishing returns" has yet to be identified.

As noted previously, the relative benefits study is still in progress and additional data and analyses are anticipated. Although some of the fine details in the results may be different when the study is completed, the conclusions presented above are likely to remain unchanged. 


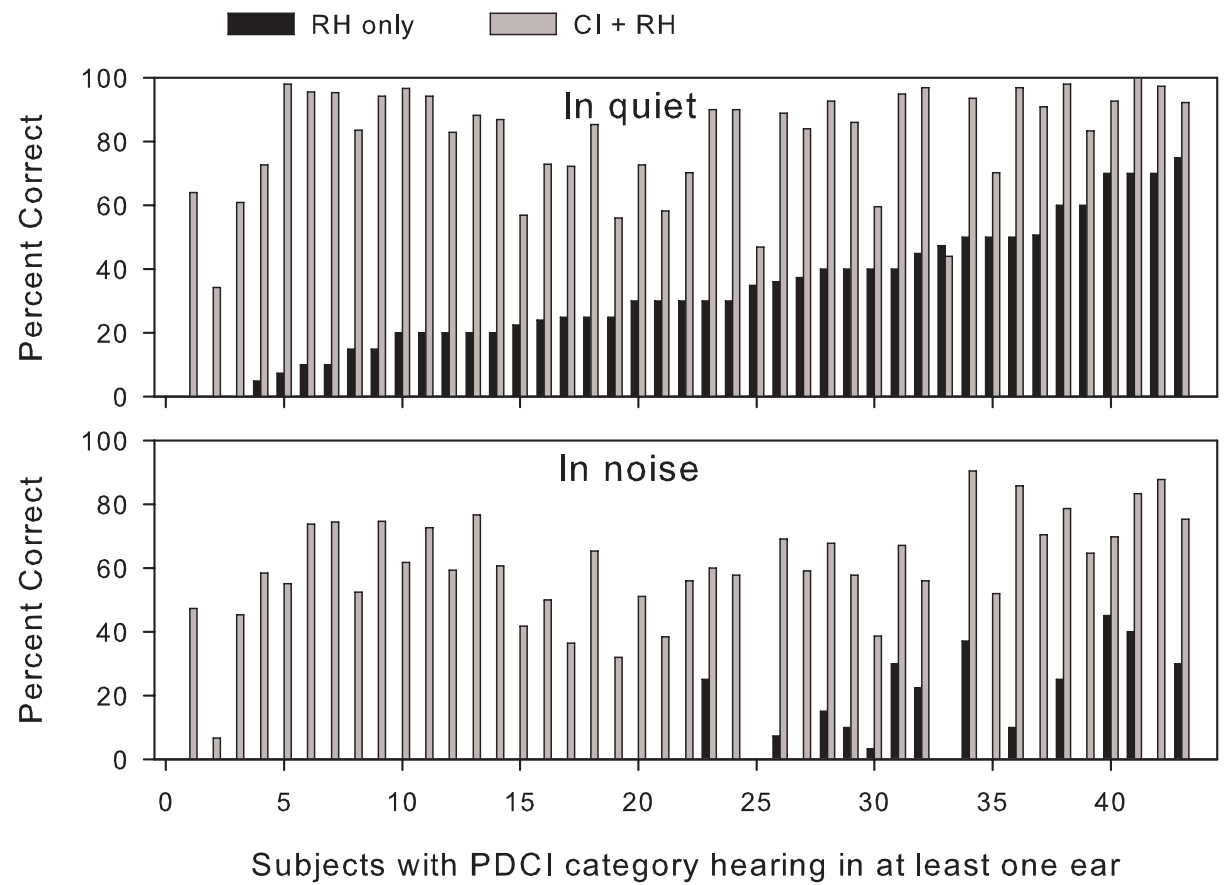

Figure 9. Individual scores for the 43 subjects in Figure 8 with PDCl-level residual hearing in at least one ear. The scores for residual hearing only are shown with the black bars ( $\mathrm{RH}$ only), and the scores for the cochlear implant plus residual hearing are shown with the gray bars $(\mathrm{Cl}+\mathrm{RH})$. Scores for recognition of the Pruszewicz monosyllabic words presented in quiet are shown in the top panel, and the scores for recognition of the words presented in competition with speech-spectrum noise at the speech-to-noise ratio of $+10 \mathrm{~dB}$ are shown in the bottom panel. The $\mathrm{x}$ axes show the subject numbers.

\section{Recommendations and view to the future}

Combined EAS and PDCI have been established as effective treatments for persons with little or no hearing at high frequencies and at least some remaining hearing at low frequencies. Highly significant benefits have been demonstrated across a wide range of residual hearing, from only a modest amount of residual hearing to high levels of residual hearing. In addition, the results to date have shown that hearing can be preserved - to a large extent and for most patients - in an operated cochlea into which an electrode array has been inserted.

Although these two treatments have been remarkably effective, questions remain about optimal combinations of electric and acoustic stimuli; the ideal depth or angle of insertion for the electrode array; whether the ideal depth may vary from patient to patient; and whether the reliability of hearing preservation in an implanted cochlea can be increased beyond the present high levels. Work is in progress to address each of these questions, and the answers may well lead to further improvements in speech reception performance and hearing preservation.

For now, the data presented in this paper seem to warrant the following recommendations: (1) modify candidacy criteria for cochlear implants to include on a routine basis persons with PDCI levels of hearing; (2) gently explore the use of cochlear implants for persons with somewhat better residual hearing than the PDCI levels, to determine the point at which a high benefit from combined EAS cannot be assured; (3) evaluate adjunctive use of a hearing aid in the contralateral ear for the large population of patients using a unilateral cochlear implant and with at least some residual hearing in the contralateral ear (also see $[10,11]$ ); and (4) preserve and use residual hearing whenever possible, as even a modest amount of residual hearing can act as a powerful adjunct to electrically elicited hearing and vice versa.

\section{Acknowledgments}

Parts of the described studies were supported by the United States' National Institutes of Health (the NIH) and by a Marie Curie Transfer of Knowledge project for the Remediation of Hearing Loss, funded by the European Commission and involving five centers in Europe including the International Center of Hearing and Speech in Kajetany, Poland, which is the coordinating center for the project. Support for patient and investigator travel for some of the studies was generously provided by Med-El GmbH of Innsbruck, Austria. The author is a consultant for Med-El. None of the statements herein favor that or any other company. This paper is based in part on a keynote (and Guest of Honor) address given at the Ninth European Symposium on Paediatric Cochlear Implantation, held in Warsaw, Poland, May 14-17, 2009. Portions of the paper are from or adapted from the paper by Wilson in the conference proceedings [4]. 


\section{References:}

1. von Ilberg C, Kiefer J, Tillein J et al: Electric-acoustic stimulation of the auditory system. New technology for severe hearing loss. ORL J Otorhinolaryngol Relat Spec, 1999; 61: 334-40

2. Skarzynski H, Lorens A, Piotrowska A: A new method of partial deafness treatment. Med Sci Monit, 2003; 9(4): CS20-24

3. Skarzynski H, Lorens A, Piotrowska A, Podskarbi-Fayette R: Results of partial deafness cochlear implantation using various electrode designs. Audiol Neurotol, 2009; 14(Suppl.1): 39-45

4. Wilson BS: Partial deafness cochlear implantation (PDCI) and electric-acoustic stimulation (EAS). Cochlear Implants Int, 2010; 11(Suppl.1): 56-66

5. Lawson D, Wilson B, Wolford R et al: Speech processors for auditory prostheses: combined electric and acoustic stimulation of the same cochlea. Eighth Quarterly Progress Report, NIH Project N01-DC-8-2105, Neural Prosthesis Program, National Institutes of Health, Bethesda, MD, USA, 2000

6. Wilson BS, Wolford RD, Lawson DT, Schatzer R: Speech processors for auditory prostheses: additional perspectives on speech reception with combined electric and acoustic stimulation. Third Quarterly Progress Report, NIH Project N01DC-2-1002, Neural Prosthesis Program, National Institutes of Health, Bethesda, MD, USA, 2002

7. Wilson BS, Lawson DT, Müller JM et al: Cochlear implants: some likely next steps. Annu Rev Biomed Eng, 2003; 5: 207-49

8. Gstoettner W, Kiefer J, Baumgartner WD: Hearing preservation in cochlear implantation for electric acoustic stimulation. Acta Oto-Laryngologica, 2004; 124: 348-52

9. Dooley GJ, Blamey PJ, Seligman PM et al: Combined electrical and acoustical stimulation using a bimodal prosthesis. Arch Otolaryngol Head Neck Surg, 1993; 119: 55-60

10. Ching TYC, Psarros C, Hill M et al: Should children who use cochlear implants wear hearing aids in the opposite ear? Ear \& Hearing, 2001; 22: 365-80

11. Morera C, Manrique M, Ramos A et al: Advantages of binaural hearing provided through bimodal stimulation via a cochlear implant and a conventional hearing aid: a 6-month comparative study. Acta Otolaryngologica, 2005; 125: 596-606
12. Skarzynski H, Lorens A: Partial deafness treatment. Cochlear Implants Int, 2010; 11(Suppl.1): 29-41

13. Gifford RH, Dorman MF, Brown CA: Psychophysical properties of low-frequency hearing: implications for perceiving speech and music via electric and acoustic stimulation. Adv Otorhinolaryngol, 2010; 67: 51-60

14. Baer T, Moore BC, Kluk K: Effects of low pass filtering on the intelligibility of speech in noise for people with and without dead regions at high frequencies. J Acoust Soci Am, 2002; 112: 1133-44

15. Kiefer J, Pok M, Adunka $\mathrm{O}$ et al: Combined electric and acoustic stimulation of the auditory system: results of a clinical study. Audiol Neurootol, 2005; 10: 134-44

16. Zhang T, Spahr AJ, Dorman MF: Frequency overlap between electric and acoustic stimulation and speech-perception benefit in patients with combined electric and acoustic stimulation. Ear \& Hearing, 2010; 31: 195-201

17. Vermeire K, Anderson I, Flynn M, Van de Heyning P: The influence of different speech processor and hearing aid settings on speech perception outcomes in electric acoustic stimulation patients. Ear \& Hearing, 2008; 29: 76-86

18. Gantz BJ, Hansen MR, Turner CW et al: Hybrid 10 clinical trial: preliminary results. Audiology \& Neurotology, 2009; 14(Suppl.1): 32-38

19. Gantz BJ, Turner CW: Combining acoustic and electrical hearing. Laryngoscope, 2003; 113: 1726-30

20. Lenarz T, Stöver T, Buechner A et al: Hearing conservation surgery using the Hybrid-L electrode. Audiol Neurotol, 2009; 14(Suppl.1): 22-31

21. James C, Albegger K, Battmer R et al: Preservation of residual hearing with cochlear implantation: how and why. Acta OtoLaryngologica, 2005; 125: 481-91

22. Gifford RH, Dorman MF, Shallop JK, Sydlowski SA: Evidence for the expansion of adult cochlear implant candidacy. Ear \& Hearing, 2010; 31: 186-94 